\title{
Effects of a cellulose mask synthesized by a bacterium on facial skin characteristics and user satisfaction
}

This article was published in the following Dove Press journal:

Medical Devices: Evidence and Research

22 June 2011

Number of times this article has been viewed

\section{Thanaporn Amnuaikit \\ Toon Chusuit \\ Panithi Raknam \\ Prapaporn Boonme}

Department of Pharmaceutical Technology, Faculty of Pharmaceutical Sciences, Prince of Songkla University, Songkhla, Thailand
Correspondence: Prapaporn Boonme Department of Pharmaceutical Technology, Faculty of Pharmaceutical Sciences, Prince of Songkla University, Songkhla $90 \mathrm{I}$ I2, Thailand

Tel +6674288842

Fax +66 7442 8I48

Email prapaporn.b@psu.ac.th
Background: Cellulose masks obtained from natural sources such as bacteria are of interest as cosmetic devices for the treatment of dry skin because they not only improve hydration of the skin, but have low toxicity and are biodegradable. The aims of this study were to determine the in vivo effects of a cellulose mask obtained from Acetobacter xylinum on skin characteristics and to evaluate user satisfaction with the product.

Methods: Thirty healthy Thai volunteers aged 21-40 years participated in the study. The volunteers were randomly separated into a control group and an experimental group. For the control group, volunteers were assigned to apply moist towels to the face for 25 minutes. For the experimental group, the volunteers were assigned to apply the masks, ie, translucent patches which could be fitted onto the face for the same period. The following week, the groups were changed over to the alternative treatment. Skin moisture, sebum, elasticity, texture, dullness, and desquamation levels were assessed using a system used for routine skin counseling before applying the trial product and five minutes after its removal. Degree of satisfaction with use of the cellulose mask was investigated using a five-point rating scale.

Results: The cellulose mask increased moisture levels in the skin significantly more than moist towels $(P<0.05)$ after a single application. No obvious effects on other skin characteristics were found. The cellulose mask product rated around $4 / 5$ on the satisfaction rating scale.

Conclusions: A single application of the trial cellulose mask enhanced moisture uptake by facial skin. Users also reported being satisfied with the trial product.

Keywords: bacterial cellulose, facial mask, skin characteristics, skin hydration, user satisfaction

\section{Introduction}

Normal skin integrity can be maintained when the skin has a moisture content of $20 \%-35 \%{ }^{1}$ In other words, skin hydration is important for healthy skin. Healthy skin protects against the effects of environmental hazards, such as ultraviolet radiation in sunlight, low humidity, and wind. ${ }^{2}$ Dry skin affects many people, occurring when skin loses its water content, causing the skin to appear dry, rough, and scaly, possibly with reddening, cracking, and itching. ${ }^{3}$ When the skin becomes dry, the epidermal layer loses its ability to retain moisture. Without protection or treatment, the skin cannot repair itself, leading to persistently dry skin. ${ }^{4}$ Several treatments can be used to restore dry skin or protect it from dryness. A topically applied moisturizer is the main treatment, which makes the epidermal layer of the skin softer and more pliable by enhancing hydration and decreasing water evaporation. Application of an occlusive mask to the skin can also improve hydration and protect against water loss 
from the epidermis. ${ }^{5}$ Masks can be produced from various sources. Cellulose masks obtained from natural sources, such as bacteria, are of interest because of their low toxicity and biodegradable properties. Acetobacter xylinum, a bacterium, can produce acid from glucose and synthesize cellulose. ${ }^{6}$ It creates cellulose from sugars and related substrates via the pentose cycle. ${ }^{7}$ Bacterial cellulose has been widely used as a stabilizer in foods and cosmetics. In the form of a film, it can be used in surgical procedures and for dental implants. ${ }^{8}$ Recently, bacterial cellulose obtained from Acetobacter xylinum culture was characterized and found to be composed of long, smooth, and oriented fibrils and to exhibit considerable thermal stability. ${ }^{9}$ Therefore, it was of interest for use as a bacterial cellulose cosmetic device, in particular as a facial mask.

The objectives of this study were to determine the in vivo efficacy of a cellulose mask obtained from Acetobacter xylinum in changing skin characteristics and to evaluate user satisfaction after a single application. The first impression of a product is usually a good indicator of user preference. If a product can provide the expected results and achieve a high level of user satisfaction after single use, it is likely that the user will purchase that product again.

\section{Materials and methods Materials}

The cellulose masks were provided by Thainanocellulose Co Ltd, Thailand. They were prepared from cellulose created by a bacterium. Briefly, broken-milled rice (Oryza sativa) was used as the feeding substrate and distilled water was used as a medium for growth of Acetobacter xylinum. Under appropriate incubation, the bacterium could synthesize cellulose. The cellulose with absorbed water obtained was cut into a face shape with holes for the eyes, nose and mouth at the correct positions. Each patch was then stored in a sealed package. The finished products were sterilized by steam in an autoclave at $121^{\circ} \mathrm{C}$ for 15 minutes. The mask patches were translucent and contained a high concentration of water. The manufacturer reported that the masks were nonirritant and satisfactory when studied in 16 Thai women. ${ }^{10}$

\section{Evaluation of efficacy}

Thirty healthy Thai volunteers aged $21-40$ years participated in testing of the efficacy of the cellulose mask for improvement of skin characteristics. The volunteers were twenty-one women and nine men. Twenty-three, five, and two volunteers were in the age ranges of 21-25, 26-30, and 31-40 years, respectively. The sample size was estimated to be sufficient to detect a difference between two population means when the probability of type I error $(\alpha)$ and that of type II error $(\beta)$ was set at 0.05 and 0.20 , respectively. The study was carried out with the approval of the ethics committee of the Faculty of Pharmaceutical Sciences at Prince of Songkla University, Songkhla, Thailand. All volunteers gave their informed written consent and underwent testing for any skin irritation that might be caused by the cellulose mask before the study. No skin irritation occurred when the cellulose mask was applied to the lateral arm for 24 hours, so all volunteers were able to be included in the study.

The experiment was done in a laboratory room where the temperature and relative humidity was controlled at $25^{\circ} \mathrm{C}$ and $50 \%$, respectively. The volunteers were randomly separated into two groups. Each group was invited to participate in the test twice. For the first test, volunteers in the group were assigned to apply moist towels to the face for 25 minutes, while volunteers in the other group were assigned to apply the trial masks to the face for the same time period. One week later the experiment was repeated, with the volunteers changing over to the alternative treatment. Skin moisture, sebum, elasticity, texture, dullness, and desquamation levels were assessed before applying the sample and five minutes after removing it using a tool normally used as part of routine skin counseling (Moritex Corporation, Tokyo, Japan). ${ }^{11}$ The skin counseling system consists of a touch screen computer with a sensor and a scope to evaluate sebum, moisture, elasticity, texture, and dullness of the skin. The values obtained are reported as percentages, and ranked as low, medium and high, in comparison with reference values in a population of the same age range provided by the manufacturer. To evaluate desquamation, a $2 \mathrm{~cm} \times 1 \mathrm{~cm}$ sample sticker was used to take skin samples. The sticker was applied to the experimental area of skin for one minute and then peeled off. Afterwards, the surface of the sticker containing a sample of the skin from each volunteer was attached to the lens window of the scope, which was then used to rate the condition of the skin. Texture, dullness, and desquamation were ranked as A, B, or C good, fair, or poor, respectively, when compared with reference values.

\section{Evaluation of user satisfaction}

At the end of the study, all volunteers completed a questionnaire rating their degree of satisfaction with the cellulose 
mask on a five-point scale (excellent $=5$, good $=4$, fair $=3$, poor $=2$, very poor $=1$ ).

\section{Statistical analysis}

The paired $t$-test and $t$-test were used to identify statistically significant differences in skin characteristics before and after using the trial product and between the trial product and the control, respectively. A $P$ value of 0.05 was considered to be statistically significant.

\section{Results}

The cellulose mask was a translucent patch which could be fitted onto the face as demonstrated in Figure 1. The skin sebum level after moist towel application was $51.43 \pm 12.24 \%$ and after using the trial cellulose mask was $50.57 \pm 12.09 \%$. The skin elasticity level after moist towel application was $44.30 \pm 12.73 \%$ and after using the trial cellulose mask was $46.70 \pm 8.78 \%$. The skin moisture content

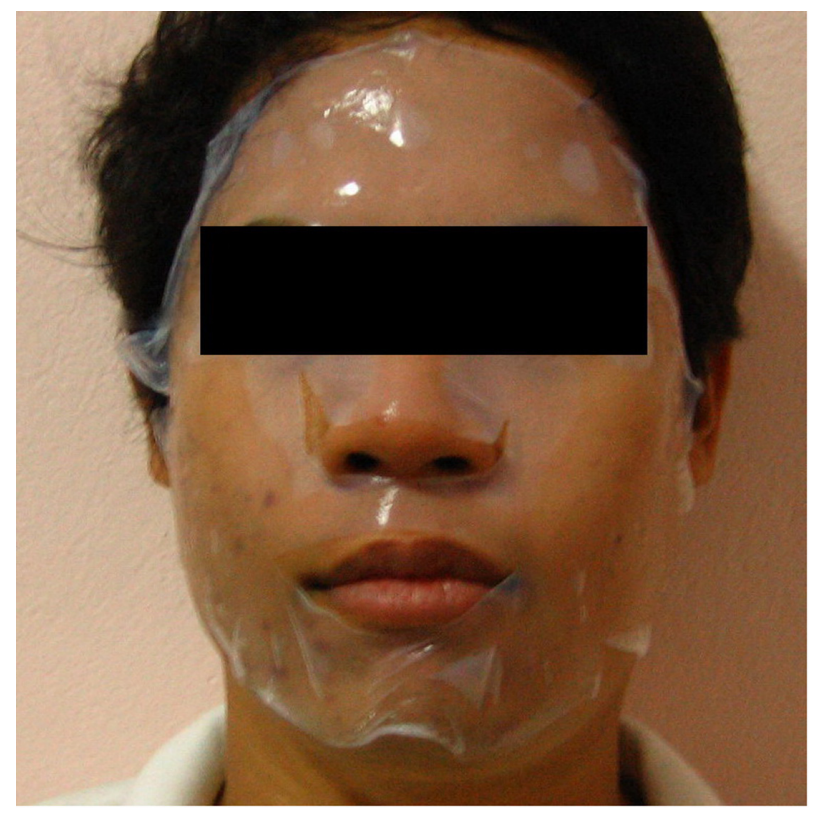

Figure I Appearance of cellulose mask when applied onto facial skin.

Table I Skin characteristics of volunteers before and after applying cellulose masks

\begin{tabular}{|c|c|c|c|c|c|c|c|c|c|c|c|c|c|c|c|c|c|}
\hline \multirow[t]{2}{*}{ Subject } & \multirow[t]{2}{*}{ Skin type } & \multicolumn{8}{|c|}{ Before application } & \multicolumn{8}{|c|}{ After application } \\
\hline & & $\mathbf{A}$ & B & C & D & $\mathbf{E}$ & $\mathbf{F}$ & G & $\mathbf{H}$ & $\mathbf{A}$ & B & C & D & $\mathbf{E}$ & $\mathbf{F}$ & G & $\mathbf{H}$ \\
\hline 1 & Oily & 51 & 46 & 42 & B & $A$ & B & $A$ & B & 83 & 44 & 59 & $C$ & $A$ & $A$ & $A$ & B \\
\hline 2 & Oily & 45 & 65 & 72 & B & A & B & $A$ & B & 49 & 56 & 95 & C & A & B & B & A \\
\hline 3 & Normal & 18 & 54 & 80 & C & A & A & $A$ & B & 15 & 40 & 87 & C & A & A & $A$ & B \\
\hline 4 & Oily & 87 & $4 I$ & 50 & $\mathrm{C}$ & $A$ & B & $A$ & B & 71 & 48 & 71 & $\mathrm{C}$ & $A$ & B & $A$ & B \\
\hline 5 & Oily & 50 & 47 & 44 & C & $A$ & A & $C$ & $B$ & 83 & 60 & 72 & $C$ & $A$ & $A$ & B & B \\
\hline 6 & Oily & 67 & 48 & 49 & $\mathrm{C}$ & $A$ & C & $A$ & B & 93 & 56 & 74 & C & B & C & B & B \\
\hline 7 & Oily & $4 I$ & 42 & 40 & B & B & A & $A$ & C & 44 & 48 & 66 & C & B & $A$ & A & A \\
\hline 8 & Normal & 24 & 28 & 71 & B & A & A & C & B & 21 & 27 & 77 & C & A & A & C & A \\
\hline 9 & Oily & 44 & 27 & 47 & B & B & A & B & C & 73 & 42 & 61 & B & B & $A$ & C & A \\
\hline 10 & Oily & 59 & 38 & 57 & C & $A$ & C & C & $A$ & 53 & 44 & 66 & C & $A$ & $C$ & C & A \\
\hline II & Oily & 98 & 33 & 40 & $\mathrm{C}$ & $A$ & B & A & C & 97 & 45 & 50 & C & $A$ & B & A & C \\
\hline 12 & Normal & 30 & 64 & 50 & B & $A$ & B & $A$ & B & 35 & 39 & 64 & $C$ & B & B & $A$ & B \\
\hline 13 & Normal & 17 & 29 & 51 & B & A & A & B & B & 39 & 30 & 60 & C & $A$ & $A$ & $A$ & B \\
\hline 14 & Normal & 35 & 30 & 42 & B & A & B & $A$ & B & 32 & 44 & 54 & B & $A$ & $A$ & $A$ & B \\
\hline 15 & Normal & 26 & 48 & 41 & $B$ & $A$ & B & $A$ & B & 21 & 48 & 58 & B & $A$ & $A$ & B & B \\
\hline 16 & Oily & 98 & 44 & 49 & B & $A$ & C & $A$ & C & 99 & 45 & 57 & B & $A$ & $B$ & B & C \\
\hline 17 & Oily & 41 & 31 & 46 & C & A & B & $A$ & C & 70 & 54 & 57 & B & $A$ & A & C & C \\
\hline 18 & Oily & 93 & 45 & 45 & $A$ & $A$ & C & $A$ & B & 94 & 55 & 54 & B & $A$ & B & $A$ & B \\
\hline 19 & Oily & 49 & 50 & 44 & B & B & $A$ & $A$ & B & 94 & 51 & 58 & C & $A$ & $A$ & $A$ & B \\
\hline 20 & Normal & 24 & 54 & 46 & $\mathrm{C}$ & $A$ & B & C & B & 92 & 48 & 58 & B & B & B & C & A \\
\hline 21 & Normal & 30 & 52 & 42 & B & B & $A$ & C & A & 35 & 51 & 57 & B & $A$ & A & $A$ & A \\
\hline 22 & Oily & 71 & 54 & 42 & B & B & A & $A$ & B & 99 & 52 & 56 & C & $A$ & $A$ & C & A \\
\hline 23 & Oily & 55 & 50 & 41 & C & B & A & B & B & 99 & 48 & 58 & B & $A$ & $A$ & A & B \\
\hline 24 & Dry & 22 & 52 & 32 & C & $A$ & B & $A$ & B & 99 & 54 & 47 & B & $A$ & B & A & B \\
\hline 25 & Oily & 56 & 32 & 41 & B & A & B & $A$ & B & 99 & 51 & 53 & C & $A$ & B & B & A \\
\hline 26 & Normal & 21 & 55 & 42 & C & A & B & $A$ & C & 36 & 56 & 52 & B & A & B & A & C \\
\hline 27 & Oily & 56 & 66 & 42 & C & $A$ & A & $A$ & C & 78 & 60 & 53 & C & $A$ & $A$ & $A$ & C \\
\hline 28 & Normal & 9 & 56 & 38 & B & $A$ & B & $A$ & $C$ & 14 & 44 & 54 & B & $A$ & $A$ & $A$ & C \\
\hline 29 & Oily & 83 & 28 & 44 & B & $A$ & A & $A$ & B & 99 & 30 & 55 & B & $A$ & $A$ & $A$ & B \\
\hline 30 & Oily & 57 & 31 & 44 & B & A & B & A & B & 86 & 31 & 54 & $A$ & A & A & A & B \\
\hline
\end{tabular}

Abbreviations: A, skin sebum level; B, skin elasticity level; C, skin moisture level; D, skin fineness; E, skin smoothness; F, skin transparency; G, degree of pigmentation; $\mathrm{H}$, keratin desquamation. 
Table 2 Answers and average scores on the questionnaire about the opinion of 30 volunteers on application of cellulose mask

\begin{tabular}{lllllll}
\hline Topic & \multicolumn{3}{l}{ Satisfaction level $^{\mathbf{a}}$} & & $\begin{array}{l}\text { Average } \\
\text { scores }\end{array}$ \\
\cline { 2 - 6 } & $\mathbf{5}$ & $\mathbf{4}$ & $\mathbf{3}$ & $\mathbf{2}$ & $\mathbf{I}$ & \\
\hline Odor of product & 6 & 16 & 8 & 0 & 0 & 3.93 \\
Color of product & 8 & 21 & 1 & 0 & 0 & 4.23 \\
Texture of product & 10 & 20 & 0 & 0 & 0 & 4.33 \\
Comfortable use & 8 & 11 & 9 & 2 & 0 & 3.83 \\
Skin hydration & 10 & 18 & 2 & 0 & 0 & 4.27 \\
Period of application & 6 & 16 & 8 & 0 & 0 & 3.93 \\
Adhesion to skin & 7 & 17 & 6 & 0 & 0 & 4.03 \\
Overall & 5 & 23 & 2 & 0 & 0 & 4.10 \\
\hline
\end{tabular}

Note: aScoring: 5 = excellent, 4 = good, $3=$ fair, $2=$ poor, $I=$ very poor.

after moist towel application was $47.33 \pm 7.81 \%$ and after using the trial cellulose mask was $61.23 \pm 10.84 \%$. It was also noted that, after using the cellulose mask, skin moisture levels increased by between $7 \%$ and $28 \%$, without changes in the other parameters, ie, sebum and elasticity levels, as shown in Table 1.

Data for skin texture and dullness and keratin desquamation are also reported in Table 1. Skin texture was defined as fineness and smoothness. There was no significant difference between grades obtained for skin texture after moist towel application and those after application of the cellulose mask. Skin dullness was defined as transparency and degree of pigmentation. Skin transparency improved in eight of the 30 volunteers $(26.7 \%)$ when using the cellulose mask. However, there was no detectable change in degree of pigmentation between the two treatments. Signs of keratin desquamation were not significantly different after moist towel application, but changed from grade $\mathrm{B}-\mathrm{C}$ to grade $\mathrm{A}$ in seven cases (23.3\%) after using the cellulose mask.

All the volunteers completed and returned their satisfaction questionnaires, the answers to which are reported in Table 2. Responses to most questions were rated around 4-5 for the cellulose mask.

\section{Discussion}

These results indicate that a single application of the cellulose mask did not significantly reduce sebum levels or increase elasticity of the skin $(P>0.05)$. However, it did significantly enhance moisture uptake $(P<0.05)$. The water content in formulations or devices used for skin hydration is an important consideration. ${ }^{12}$ Like many moisturizers, cellulose masks can absorb moisture from the environment. ${ }^{13}$ Using the cellulose mask, absorption of moisture by the skin occurred due to the high concentration gradient of water between the mask and the skin.
The occlusive effect of the cellulose mask administered to facial skin for 25 minutes can reduce transepidermal water loss,${ }^{14}$ with efficacy of moisture uptake varying according to the skin condition of the individual volunteers.

The increased skin moisture content achieved by the cellulose mask did not improve skin texture, dullness, and desquamation significantly when compared with moist towel application $(P>0.05)$. Only water acted as an active compound in the cellulose masks. In addition, the volunteers applied the masks only once. Therefore, the full effects on skin characteristics could not be assessed. However, a minority of the volunteers did achieve improved skin transparency and desquamation after applying the cellulose mask, the reasons for which are unclear. It is possible that different subjects responded differently to hydration after topical application of the cellulose mask depending on their general health, skin condition, age, gender, and possibly other factors. In a previous study, it was reported that eight of thirty-four volunteers had a significantly greater reduction in eye puffiness after application of caffeine gel than after placebo $(P<0.05)$, while most volunteers did not show a differential response to these two products. ${ }^{15}$

The results from our questionnaires demonstrated that the odor, color, and texture of the cellulose masks were acceptable to the subjects, the majority of whom rated the cellulose mask comfortable to use and able to provide skin hydration within an acceptable period. The cellulose mask adhered well to the skin. Overall, user satisfaction with the cellulose mask was rated as good. In the future, it is possible that cosmetically active compounds, eg, for skin-whitening and antiageing, will be able to be incorporated into such cellulose masks as nanoformulations, which are likely to meet user demands further. ${ }^{16,17}$

\section{Conclusion}

The cellulose mask derived from Acetobacter xylinum could be used as a natural cosmetic product in order to increase moisture uptake in the skin. The mask was shown to be safe and effective. Single application of the cellulose mask significantly enhanced moisture uptake by the skin when compared with moist towel application $(P<0.05)$. However, it did not change skin characteristics to a significant degree. The responses to the satisfaction questionnaire used in this trial suggest that the cellulose mask is acceptable to users.

\section{Acknowledgments}

Sombat Rungsilp from Thainanocellulose Co Ltd, Thailand, is thanked for supplying the cellulose masks used in this study. 
This research was funded by the Southern Thailand Science Park, Prince of Songkla University, Songkhla, Thailand.

\section{Disclosure}

The authors report no conflicts of interest in this work.

\section{References}

1. Draelos ZD. Therapeutic moisturizers. Dermatol Clin. 2000;18: 597-607.

2. Johnson AW. Cosmeceuticals: function and the skin barrier. In: Draelos ZD, editor. Procedures in Cosmetic Dermatology Series: Cosmeceuticals. 1st ed. Philadelphia, PA: Elsevier; 2005.

3. Lazar AP, Lazar P. Dry skin, water, and lubrication. Dermatol Clin. 1991;9:45-51.

4. Rawlings AV, Matts PJ. Stratum corneum moisturization at the molecular level: an update in relation to the dry skin cycle. J Invest Dermatol. 2005;124:1099-1110.

5. Flynn TC, Petros J, Clark RE, et al. Dry skin and moisturizers. Clin Dermatol. 2001;19:387-392.

6. Gromet-Elhanan Z, Hestrin S. Synthesis of cellulose by Acetobacter xylinum VI: growth on citric acid-cycle intermediates. J Bacteriol. 1963;85:284-292.

7. Schramm M, Gromet Z, Hestrin S. Synthesis of cellulose by Acetobacter xylinum 3: substrates and inhibitors. Biochem J. 1957;67:669-679.

8. Jonas R, Farah LF. Production and application of microbial cellulose. Polym Degrad Stab. 1998;59:101-106.
9. Surma-Elusarska B, Presler S, Danielewicz D. Characteristics of bacterial cellulose obtained from Acetobacter xylinum culture for application in papermaking. Fibres and Textiles. 2008;16:108-111.

10. Thainanocellulose Co Ltd. Efficacy evaluation of Difference ${ }^{\circledR}$ facial mask in female labors of food and furniture industries. Phatthalung Province: Thainanocellulose Co Ltd; nd. Available from: www. thainanocellulose.com/file_download/report1.pdf. Accessed June 14, 2011.

11. Moritex USA Inc. Étude: the way to skin counselling; operation manual. San Jose, CA: Moritex USA, Inc; nd. Available from: www.moritexusa com/files/etude_manual.pdf. Accessed June 14, 2011.

12. Boonme P. Applications of microemulsions in cosmetics. J Cosmet Dermatol. 2007;6:223-228.

13. Leite e Silva VR, Schulman MA, Ferelli C, et al. Hydrating effects of moisturizer active compounds incorporated into hydrogels: in vivo assessment and comparison between devices. J Cosmet Dermatol. 2009; 8:32-39.

14. Suetake T, Sasai S, Zhen YX, et al. Effects of silicone gel sheet on the stratum corneum hydration. Br J Plast Surg. 2000;53:503-507.

15. Amnuaikit T, Maneenuan D, Boonme P. Evaluation of caffeine gels on physicochemical characteristics and in vivo efficacy in reducing puffy eyes. J App Pharm Sci. 2011;1:56-59.

16. Boonme P, Junyaprasert VB, Suksawad N, et al. Microemulsions and nanoemulsions: novel vehicles for whitening cosmeceuticals. J Biomed Nanotechnol. 2009;5:373-383.

17. Boonme P, Yotsawimonwat S. Anti-ageing microemulsions and nanoemulsions. HPC Today. 2011;5:42-46.
Medical Devices: Evidence and Research

\section{Publish your work in this journal}

Medical Devices: Evidence and Research is an international, peerreviewed, open access journal that focuses on the evidence, technology, research, and expert opinion supporting the use and application of medical devices in the diagnosis, treatment and management of clinical conditions and physiological processes. The identification of novel

\section{Dovepress}

devices and optimal use of existing devices which will lead to improved clinical outcomes and more effective patient management and safety is a key feature. The manuscript management system is completely online and includes a quick and fair peer-review system. Visit http://www. dovepress.com/testimonials.php to read real quotes from authors. 